Article

\title{
Influence of the Synthesis Method for Pt Catalysts Supported on Highly Mesoporous Carbon Xerogel and Vulcan Carbon Black on the Electro-Oxidation of Methanol
}

\author{
Cinthia Alegre, María Elena Gálvez, Rafael Moliner and María Jesús Lázaro * \\ Instituto de Carboquímica (CSIC), Miguel Luesma Castán 4, 50018 Zaragoza, Spain; \\ E-Mails: cinthia@icb.csic.es (C.A.); megalvez@icb.csic.es (M.E.G.); rmoliner@icb.csic.es (R.M.) \\ * Author to whom correspondence should be addressed; E-Mail: mlazaro@icb.csic.es; \\ Tel.: +34-976-733-977; Fax: +34-976-733-318.
}

Academic Editor: Keith Hohn

Received: 21 January 2015 / Accepted: 28 February 2015 / Published: 13 March 2015

\begin{abstract}
Platinum catalysts supported on carbon xerogel and carbon black (Vulcan) were synthesized with the aim of investigating the influence of the characteristics of the support on the electrochemical performance of the catalysts. Three synthesis methods were compared: an impregnation method with two different reducing agents, sodium borohydride and formic acid, and a microemulsion method, in order to study the effect of the synthesis method on the physico-chemical properties of the catalysts. X-ray diffraction and transmission electron microscopy were applied. Cyclic voltammetry and chronoamperometry were used for studying carbon monoxide and methanol oxidation. Catalysts supported on carbon xerogel presented higher catalytic activities towards $\mathrm{CO}$ and $\mathrm{CH}_{3} \mathrm{OH}$ oxidation than catalysts supported on Vulcan. The higher mesoporosity of carbon xerogel was responsible for the favored diffusion of reagents towards catalytic centers.
\end{abstract}

Keywords: Pt catalysts; methanol electro-oxidation; carbon xerogel; carbon black

\section{Introduction}

Carbon materials such as charcoals, activated carbons, carbon blacks and graphite have been widely used as support in the synthesis of catalysts with important applications in the chemical industry [1]. The 
properties of such supports, as well as their porous structure and surface chemistry, influence the dispersion and stability of the metal employed as active phase, determining the activity of the catalyst $[2,3]$.

In the field of fuel cells, electrocatalysts are responsible for the oxidation of the fuel (hydrogen, methanol, etc.) at the anode, and the reduction of oxygen at the cathode, thus generating electrical power. In PEMFC the catalysts are usually based on Pt and supported on carbon black with high surface area. In the last few decades, growing literature has appeared concerning new carbon supports such as carbon nanotubes [3], carbon nanofibers [4], ordered mesoporous carbons and carbon xerogels and aerogels $[2,5,6]$. These materials could lead to the production of more stable and highly active catalysts, with low platinum loadings $\left(<0.1 \mathrm{mg} \cdot \mathrm{cm}^{-2}\right)$ and therefore low cost [7].

Direct methanol fuel cells (DMFCs) are very promising for portable devices [2], given the ease of use of a liquid fuel, which is easily storable and transportable. However the commercialization of DMFCs is still hindered by some technical challenges, mainly: (1) slow kinetics of both the oxygen reduction and the methanol oxidation and (2) methanol crossover [2]. For these reasons, improved catalysts are required. Research is mainly focusing on (i) the development of new catalyst syntheses taking into account alloy composition, nanometric dimensions and uniform distribution of the catalyst and (ii) the development of new carbon supports with high electric conductivity, high surface area and high mesoporosity in the pore size range of 20-40 $\mathrm{nm}$ [5].

Carbon gels are materials with interesting properties to be used as electrocatalyst supports in fuel cells (FC). Carbon xerogels in particular are attracting much attention for their unique and controllable properties (high surface area and mesoporosity with narrow pore size distribution as well as high purity $(>99.5 \% \mathrm{C})$ ) which, in turn, are attributed to the mechanism reaction, being similar to the sol-gel process [8].

In a previous work [9], Pt and PtRu catalysts supported on carbon xerogels (CXGs) were synthesized. Carbon supports presented high surface area and pore volume values, $577 \mathrm{~m}^{2} \cdot \mathrm{g}^{-1}$ and $1.82 \mathrm{~cm}^{3} \cdot \mathrm{g}^{-1}$ respectively, with pore size equal to $7.1 \mathrm{~nm}$. Pt/CXG and PtRu/CXG catalysts presented higher catalytic activities than commercial ones, namely $\mathrm{Pt} / \mathrm{C}$ and $\mathrm{PtRu} / \mathrm{C}$ from E-TEK. The present work involves the synthesis of a carbon xerogel with improved properties (higher surface area, $660 \mathrm{~m}^{2} \cdot \mathrm{g}^{-1}$ and larger pore size, $23 \mathrm{~nm}$ ), to be used as $\mathrm{Pt}$ support. In order to compare the results obtained, $\mathrm{Pt}$ nanoparticles were also deposited on a commercial carbon black (Vulcan-XC-72R). Also, three different synthetic methods were assessed given that the catalyst preparation procedure has a strong influence on its final properties. It is necessary to optimize each synthesis method, taking into consideration the particular characteristics of the support, in order to obtain a properly dispersed active phase, with the most appropriate crystal size.

\section{Results and Discussion}

\subsection{Textural and Chemical Characterization}

\subsubsection{Characterization of the Carbon Supports}

Table 1 presents the textural properties of the carbon supports, determined from their corresponding nitrogen adsorption isotherms. Carbon supports were called " $\mathrm{CXG}$ " for carbon xerogels and "Vulcan", for the commercial carbon black. Significantly higher values of surface area $\left(660 \mathrm{~m}^{2} \cdot \mathrm{g}^{-1}\right)$ and pore volume $\left(1.79 \mathrm{~cm}^{3} \cdot \mathrm{g}^{-1}\right)$ were obtained for the carbon xerogel, in comparison to those determined for Vulcan carbon black $\left(224 \mathrm{~m}^{2} \cdot \mathrm{g}^{-1}\right)$, pointing to a more developed porous structure in the case of the CXG. 
Table 1. Carbon support textural properties.

\begin{tabular}{|c|c|c|c|c|c|c|c|c|c|}
\hline \multirow[b]{2}{*}{ Sample } & \multirow{2}{*}{$\begin{array}{c}S_{\mathrm{BET}} \\
\left(\mathrm{m}^{2} \cdot \mathrm{g}^{-1}\right)\end{array}$} & \multirow{2}{*}{$\begin{array}{c}\text { Total pore volume } \\
(0.7-180 \mathrm{~nm})\left(\mathrm{cm}^{3} \cdot \mathrm{g}^{-1}\right)\end{array}$} & \multicolumn{3}{|c|}{ Micropore volume $\left(\mathrm{cm}^{3} \cdot \mathrm{g}^{-1}\right)$} & \multicolumn{3}{|c|}{ Mesopore volume $\left(\mathrm{cm}^{3} \cdot \mathrm{g}^{-1}\right)$} & \multirow{2}{*}{$\begin{array}{l}\text { Average pore } \\
\text { size }(\mathbf{n m})\end{array}$} \\
\hline & & & $\begin{array}{c}V_{\text {micro }} \\
(0-0.7 \mathrm{~nm}) \\
\end{array}$ & $\begin{array}{c}V_{\text {micro }} \\
(0.7-2 \mathrm{~nm}) \\
\end{array}$ & $\begin{array}{c}V_{\text {micro }} \\
(0-2 \mathrm{~nm}) \\
\end{array}$ & $\begin{array}{c}V_{\text {meso }} \\
(2-25 \mathrm{~nm}) \\
\end{array}$ & $\begin{array}{c}V_{\text {meso }} \\
(25-300 \mathrm{~nm}) \\
\end{array}$ & $\begin{array}{c}V_{\text {BJH }} \\
(1.5-300 \mathrm{~nm}) \\
\end{array}$ & \\
\hline Vulcan & 224 & 0.47 & 0.01 & 0.03 & 0.04 & 0.24 & 0.17 & 0.41 & 11.0 \\
\hline CXG & 660 & 1.79 & 0.06 & 0.07 & 0.13 & 0.97 & 0.69 & 1.66 & 23.3 \\
\hline
\end{tabular}

Table 2. Catalysts textural properties.

\begin{tabular}{|c|c|c|c|c|c|c|c|c|c|}
\hline \multirow[b]{2}{*}{ Sample } & \multirow{2}{*}{$\begin{array}{c}S_{\mathrm{BET}} \\
\left(\mathrm{m}^{2} \cdot \mathrm{g}^{-1}\right)\end{array}$} & \multirow{2}{*}{$\begin{array}{c}\text { Total pore volume } \\
(0.7-180 \mathrm{~nm})\left(\mathrm{cm}^{3} \cdot \mathrm{g}^{-1}\right)\end{array}$} & \multicolumn{3}{|c|}{ Micropore volume $\left(\mathrm{cm}^{3} \cdot \mathrm{g}^{-1}\right)$} & \multicolumn{3}{|c|}{ Mesopore volume $\left(\mathrm{cm}^{3} \cdot \mathrm{g}^{-1}\right)$} & \multirow{2}{*}{$\begin{array}{l}\text { Average pore } \\
\text { size }(\mathbf{n m})\end{array}$} \\
\hline & & & $\begin{array}{c}V_{\text {micro }} \\
(0-0.7 \mathrm{~nm}) \\
\end{array}$ & $\begin{array}{c}V_{\text {micro }} \\
(0.7-2 \mathrm{~nm}) \\
\end{array}$ & $\begin{array}{c}V_{\text {micro }} \\
(0-2 \mathrm{~nm}) \\
\end{array}$ & $\begin{array}{c}V_{\text {meso }} \\
(2-25 \mathrm{~nm}) \\
\end{array}$ & $\begin{array}{c}V_{\text {meso }} \\
(25-300 \mathrm{~nm}) \\
\end{array}$ & $\begin{array}{c}V_{\text {BJH }} \\
(\mathbf{1 . 5}-\mathbf{3 0 0} \mathbf{~ n m}) \\
\end{array}$ & \\
\hline Pt/Vulcan-SBM & 187 & 0.47 & 0.02 & 0.01 & 0.03 & 0.21 & 0.21 & 0.42 & 14.8 \\
\hline Pt/Vulcan-FAM & 191 & 0.38 & 0.02 & 0.01 & 0.03 & 0.20 & 0.13 & 0.33 & 11.9 \\
\hline Pt/Vulcan-ME & 177 & 0.35 & 0.02 & 0.01 & 0.03 & 0.17 & 0.15 & 0.32 & 10.3 \\
\hline Pt/CXG-SBM & 475 & 1.34 & 0.07 & 0.05 & 0.12 & 0.45 & 0.77 & 1.22 & 24.5 \\
\hline Pt/CXG-FAM & 478 & 1.08 & 0.09 & 0.05 & 0.14 & 0.34 & 0.59 & 0.93 & 23.5 \\
\hline Pt/CXG-ME & 349 & 1.27 & 0.06 & 0.04 & 0.10 & 0.38 & 0.77 & 1.15 & 25.5 \\
\hline
\end{tabular}


Although the average pore size measured for the carbon xerogel, $23.3 \mathrm{~nm}$, is higher than the value obtained for the carbon black, $11 \mathrm{~nm}$, both carbon materials are predominantly mesoporous. BJH-mesopore volumes are $1.66 \mathrm{~cm}^{3} \cdot \mathrm{g}^{-1}$ (for the $\mathrm{CXG}$ ) and $0.41 \mathrm{~cm}^{3} \cdot \mathrm{g}^{-1}$ (for Vulcan), much more relevant than their respective micropore contributions, which become almost negligible in the case of the carbon black. In carbon aerogels and xerogels, micropores are related to the stacking arrangement of the aromatic layers that compose the primary particles of their structure, with a particle size of 3-25 nm [10]. In their three-dimensional arrangement, mesopores appear as a consequence of the void space and interconnections among these primary particles [6]. As shown in Table 1, t-plot analysis of the adsorption isotherms yielded similar values for mesopore volume in the range of 2 to $25 \mathrm{~nm}$ as for wider mesopores and macropores, 25-300 nm, in the case of the carbon black. However, for the synthesized carbon xerogel, narrow mesopores (in the range of 2 to $25 \mathrm{~nm}$ ) represent a relatively higher fraction of the total mesopore volume. Abundance of mesopores in the structure of these materials favors, in principle, their application as supports in the preparation of Pt-based electrocatalysts. Pores in the range of wide mesopores ensure an adequate deposition of the active phase, avoiding pore blockage, and facilitating both the access of the reactants to the metallic sites and the diffusion of the products out of the porous structure of the catalyst $[5,11,12]$.

\subsubsection{Catalyst Characterization}

Table 2 shows the textural properties obtained from their corresponding nitrogen adsorption isotherms for the several catalysts prepared, using both the carbon black Vulcan and the carbon xerogel, and following the different synthetic routes for $\mathrm{Pt}$ deposition. Impregnation and microemulsion synthetic methods were employed to support Pt nanoparticles on the different carbon materials. Impregnation and reduction with formic acid (FAM) or sodium borohydride (SBM) were employed as general synthetic methods, whereas a microemulsion based method (ME) was introduced as a new synthetic route not previously used for carbon xerogels. In general, surface area decreases notably after Pt-loading, as a consequence of partial blockage of the porous structure of the carbon materials. In spite of this, the prepared electrocatalysts show areas in the $177-478 \mathrm{~m}^{2} \cdot \mathrm{g}^{-1}$ range, higher in the case of the ones prepared using the carbon xerogel in comparison to Vulcan, due to the more developed porous structure of the starting carbon material.

Micropore volume remains almost constant upon the introduction of the metallic component, with a slight reduction in the amount of wide micropores, which become partially blocked by the deposition of Pt particles of lower size. On the other hand, metal loading affects mostly the mesopore volume of the carbon supports, depending on the initial porous structure of each material and the synthesis method employed for the preparation of the catalyst. Mesopore volume decreases as a consequence of the introduction of the active phase, but this decrease is more noticeable in the case of the catalysts prepared using formic acid as a reducing agent. Following the borohydride synthesis route, Pt-deposition using carbon black as support results in only a slight blockage of narrow mesoporosity. The use of formic acid results in a more extensive pore blockage, either in the case of employing the Vulcan carbon black or the carbon xerogel as supports. A wider range of mesopore sizes, 30-60 nm, was affected by introduction of the metallic active phase when following the formic acid synthesis route, vis-á-vis the use of sodium borohydride as reducing agent. On the other hand, pore volume and 
surface area decrease dramatically in the case of the catalysts prepared through the microemulsion method. In this last case, micropore volume is totally blocked upon active phase loading. This can be due to the presence of some remains of the surfactant employed within the synthesis of this catalyst, which remain bonded to the carbon surface, as evidenced in TGA oxidation of this catalyst (not shown). The presence of this material, even upon extensive washing, still blocks part of the porous structure of the support.

Figure 1 shows the X-Ray patterns for the prepared electrocatalysts. Peaks observed indicate the presence of the face-centered cubic (fcc) structure typical of Pt and represented by the (111), (200), (220) facets.

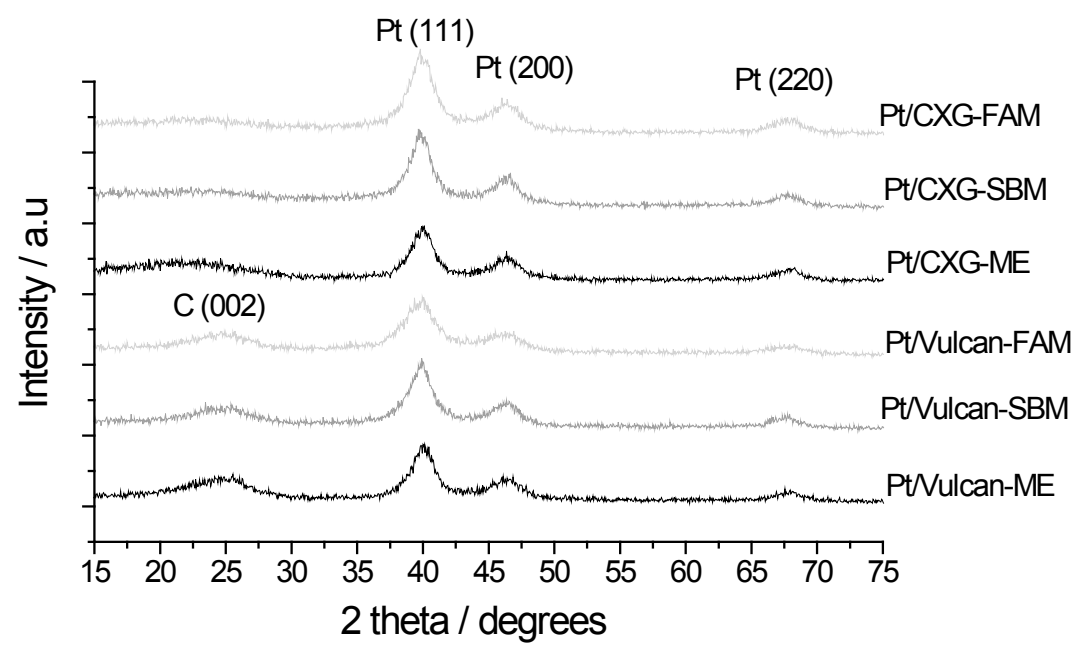

Figure 1. XRD patterns for the assessed catalysts.

Scherrer's equation was applied to (220) reflectances for the calculation of Pt particle size in each case. Crystallite sizes obtained range from 3.4 to $4.6 \mathrm{~nm}$, as presented in Table 3. Broader peaks correspond, according to Scherrer's law, to small average crystal sizes. The broadening of the peaks evidences also lower crystallinity, typical of small particles having lattice strain [13]. Pt crystal size increases for the catalysts prepared using sodium borohydride as reducing agent in the case of using $\mathrm{CXG}$ as support, whereas the opposite effect is encountered for the carbon black support.

Table 3. Crystallite size obtained by XRD and percentage of metal (weight) deposited measured by ICP-AES.

\begin{tabular}{ccc}
\hline Catalysts & Pt crystal size (nm) & \% Pt (ICP-AES) \\
\hline Pt/CXG-SBM & 4.2 & 20.2 \\
Pt/CXG-FAM & 3.6 & 17.9 \\
Pt/CXG-ME & 3.9 & 17.1 \\
$\mathrm{Pt} /$ Vulcan-SBM & 3.4 & 16.8 \\
$\mathrm{Pt} /$ Vulcan-FAM & 4.6 & 16.7 \\
Pt/Vulcan-ME & 4.4 & 17.4 \\
\hline
\end{tabular}

Pt catalysts were characterized by ICP-AES (Table 3) to determine the percentage of metal deposited. The metallic loading ranges from $16 \%$ to $20 \%$ (weight). As can be seen in the micrographs obtained by TEM (Figure 2), catalysts present different particle distribution. In principle, the synthetic 
route using formic acid provides the catalysts with a more adequate Pt-distribution, independently from the support (Figure 2b,d) with average particle sizes centered at $2.7 \mathrm{~nm}$ in both cases (see histograms). Synthesis by means of the borohydride route, Figure 2a,e, shows the presence of both isolated particles of lower size and agglomerates of particles in the case of the $\mathrm{CXG}$, where a bimodal particle size distribution is observed: one peak is centered around $3.2 \mathrm{~nm}$ and another about $4.5 \mathrm{~nm}$. In the case of Vulcan, there is also some presence of particle agglomerates, with particle size distribution centered around $2.8 \mathrm{~nm}$. The microemulsion route leads to Pt-particles that tend to agglomerate, forming chain-like structures (Figure 2c,f) although particles appear to be individually slightly smaller than in the other cases, with an average size centered at $3.6 \mathrm{~nm}$ for Vulcan and at $4.3 \mathrm{~nm}$ for the CXG.
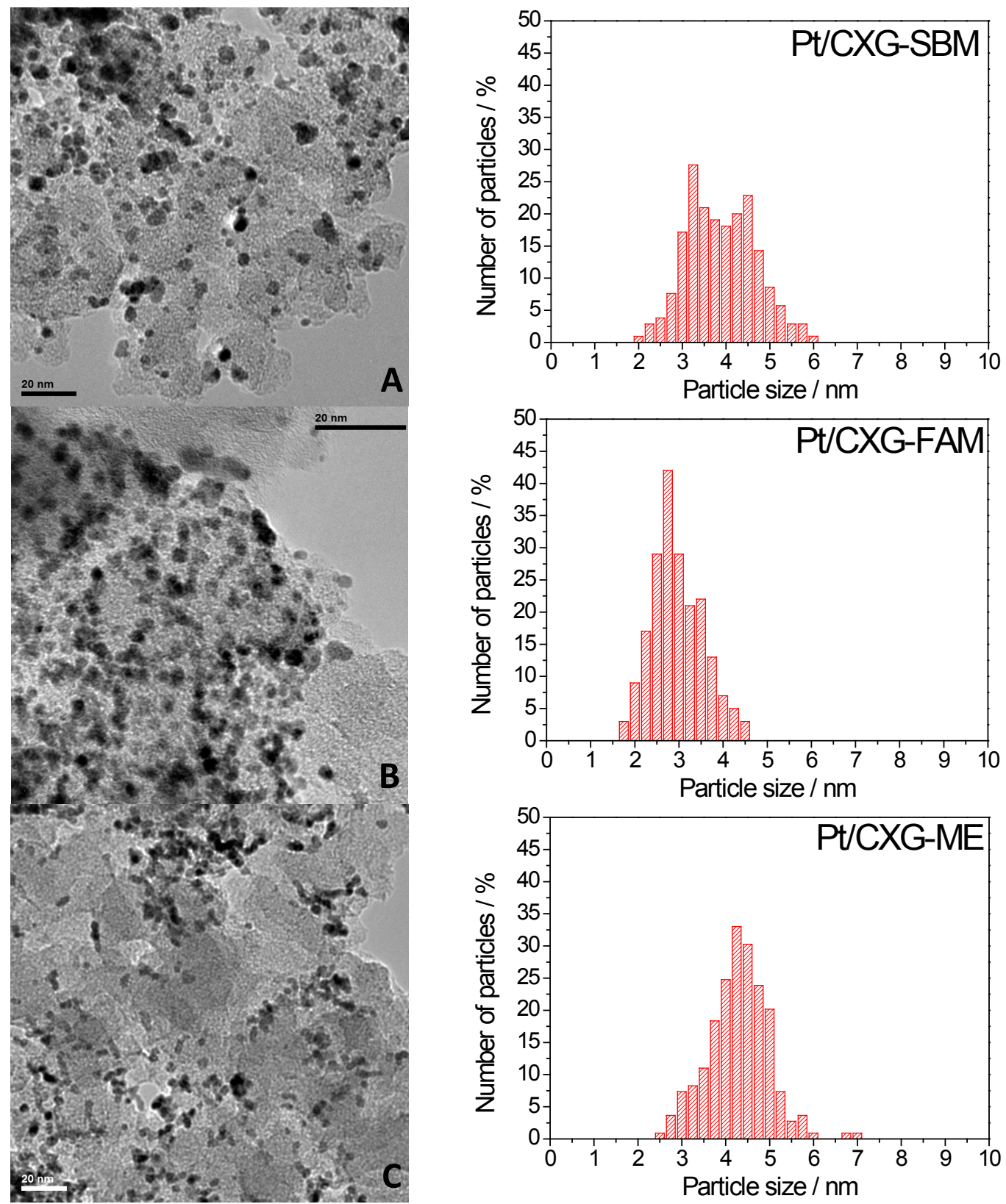

Figure 2. Cont. 

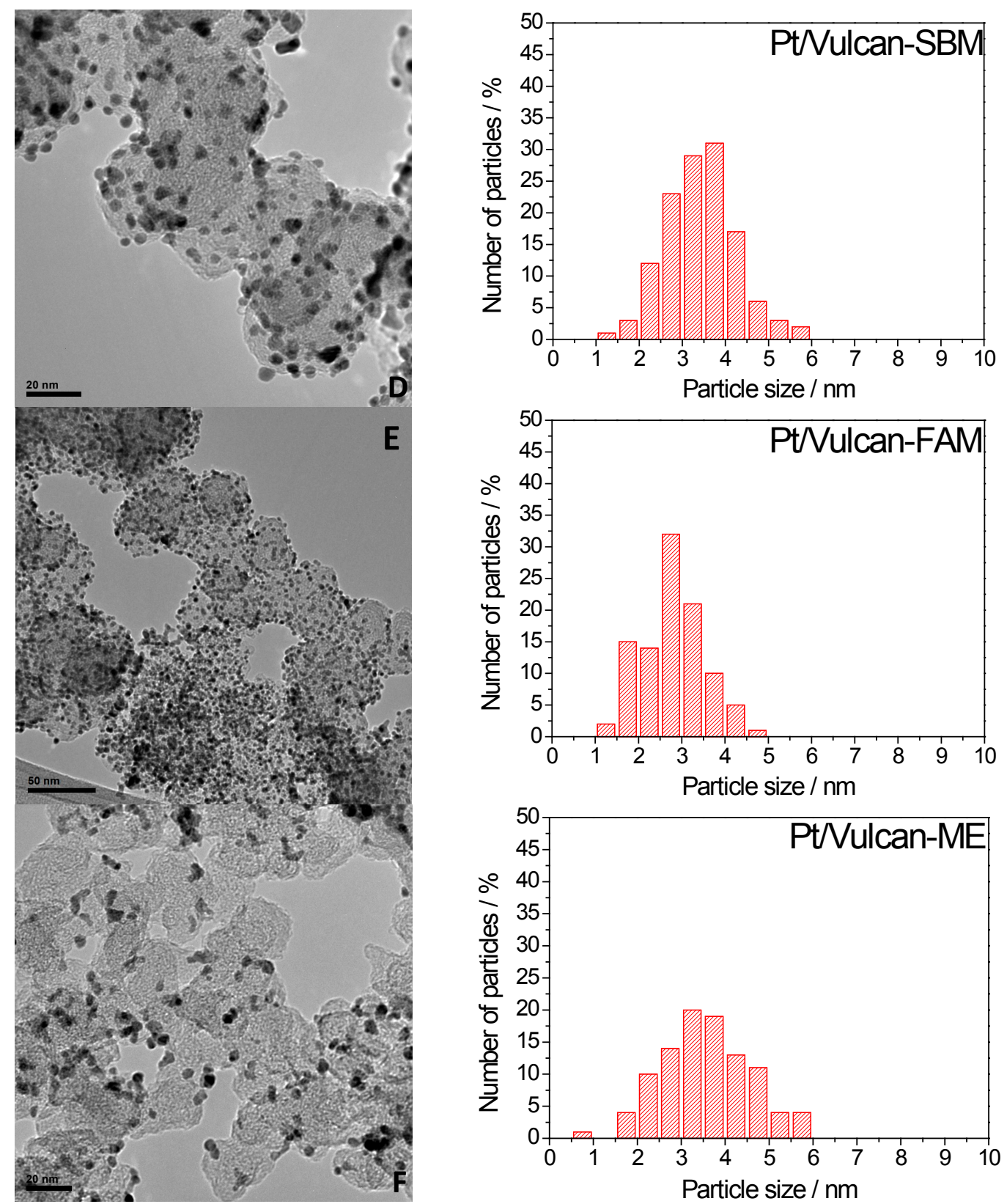

Figure 2. TEM images and corresponding histograms for (a) Pt/CXG-SBM; (b) Pt/CXG-FAM; (c) Pt/CXG-ME; (d) Pt/Vulcan-SBM; (e) Pt/Vulcan-FAM; and (f) Pt/Vulcan-ME.

\subsection{Electrochemical Characterization}

Pt catalysts were characterized by cyclic voltammetry, and CO stripping was performed in order to establish the influence of the support on the potential for its oxidation. Figure 3 shows the CO-stripping voltammograms obtained for the assessed catalysts. Two scans were performed: during the first one, $\mathrm{CO}$ was oxidized; whereas the second one is equivalent to the voltammogram in the base electrolyte.

The COads oxidation peak potential of Pt supported onto both carbon supports was obtained around 0.81-0.83 V vs. RHE, for the catalysts synthesized by impregnation methods. However, for the catalysts synthesized by the microemulsion method, the COads oxidation peak potential occurred at more negative potentials, $(0.78 \mathrm{~V}$ vs. RHE) along with another oxidation peak at low potentials 
(0.70 V vs. RHE). Maillard and co-workers [14] investigated the performance of carbon black supported catalysts with different degrees of metallic agglomeration towards the electro-oxidation of CO. They observed that in fact CO monolayer oxidation was strongly influenced by Pt particle size. They reported remarkable activity for $\mathrm{Pt}$ agglomerates in comparison to isolated $\mathrm{Pt}$ particles or polycrystalline $\mathrm{Pt}$, catalysing $\mathrm{CO}$ oxidation at considerably lower overpotentials.
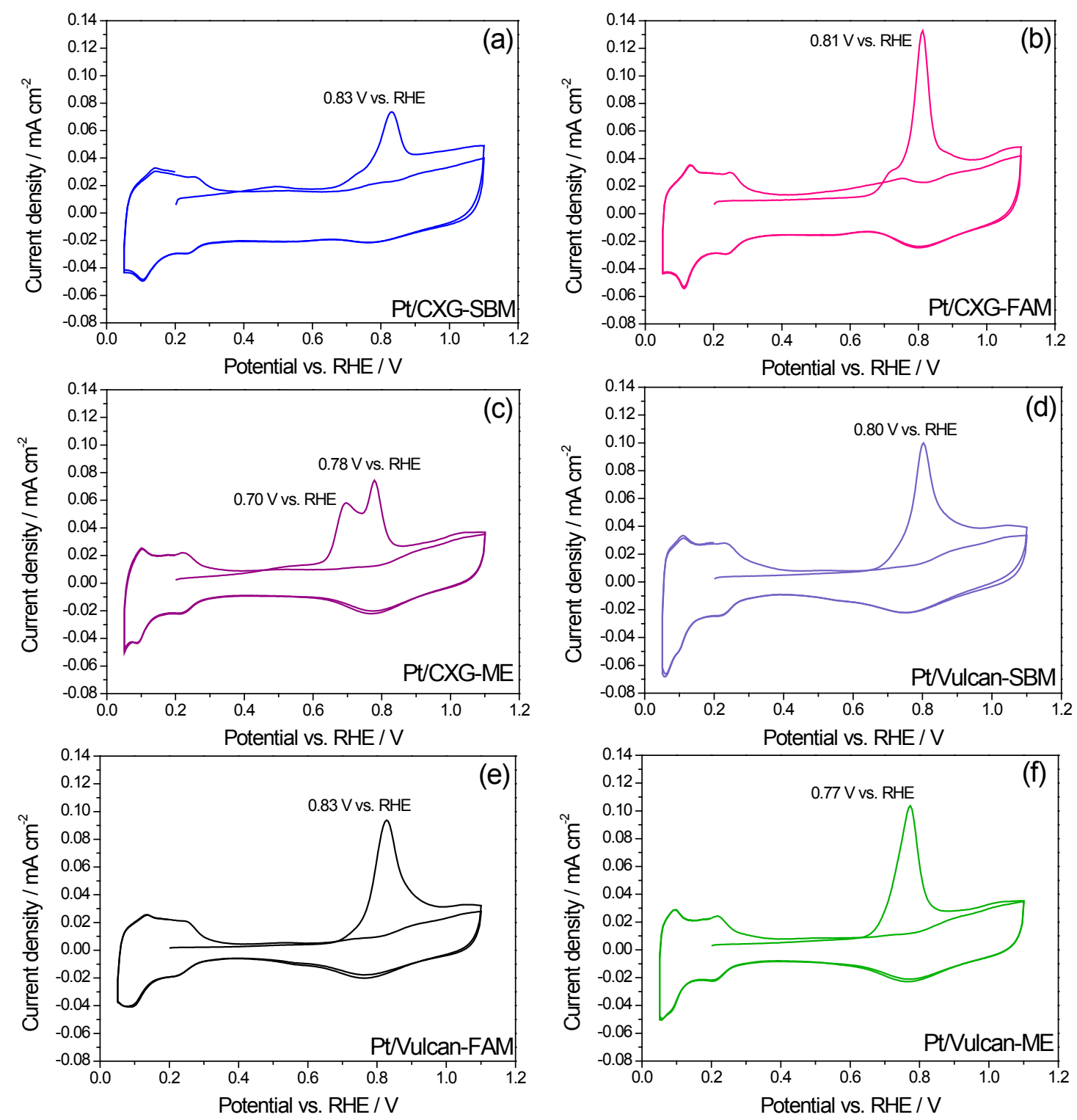

Figure 3. CO stripping voltammograms for (a) Pt/CXG-SBM; (b) Pt/CXG-FAM; (c) Pt/CXG-ME; (d) Pt/Vulcan-SBM; (e) Pt/Vulcan-FAM; and (f) Pt/Vulcan-ME.

CO stripping was also employed to determine the electrochemical Pt active areas (ECSA) as shown in Table 4. Catalysts show similar ECSA values between 36.5 and $47.9 \mathrm{~m}^{2} \cdot \mathrm{g}^{-1}$, except for Pt/Vulcan-ME, which shows a much lower ECSA, $14.7 \mathrm{~m}^{2} \cdot \mathrm{g}^{-1}$. As previously shown in TEM micrographs, this catalyst showed the worst particle distribution, which is responsible for this low ECSA. Contrary to expectations, catalysts with the lowest crystal size do not present the highest ECSA. 
Table 4. ECSA obtained from CO stripping and peak mass activity for methanol oxidation.

\begin{tabular}{ccccc}
\hline Catalysts & $\begin{array}{c}\text { Pt crystal } \\
\text { size }(\mathbf{n m})\end{array}$ & ECSA $\left(\mathbf{m}^{\mathbf{2}} \cdot \mathbf{g}^{-\mathbf{1}}\right)$ & $\begin{array}{c}\text { Peak mass activity } \\
\left(\mathbf{A} \cdot \mathbf{g}^{-\mathbf{1}} \mathbf{P t}\right)\end{array}$ & $\begin{array}{c}\text { Peak specific activity } \\
\left(\mathbf{m A} \cdot \mathbf{c m}^{-\mathbf{2}} \mathbf{P t}\right)\end{array}$ \\
\hline Pt/CXG-SBM & 4.2 & 47.9 & 363 & 0.96 \\
Pt/CXG-FAM & 3.6 & 38.6 & 367 & 1.13 \\
Pt/CXG-ME & 3.9 & 36.5 & 470 & 1.29 \\
Pt/Vulcan-SBM & 3.4 & 39.2 & 330 & 0.84 \\
Pt/Vulcan-FAM & 4.6 & 41.4 & 300 & 0.47 \\
Pt/Vulcan-ME & 4.4 & 14.7 & 232 & 1.58 \\
\hline
\end{tabular}

The behavior of the electrocatalysts towards the oxidation of methanol was studied in a deaerated $2 \mathrm{M} \mathrm{CH}_{3} \mathrm{OH}+0.5 \mathrm{M} \mathrm{H}_{2} \mathrm{SO}_{4}$ solution. Resulting cyclic voltammograms recorded are shown in Figure 4. Table 4 also shows the peak activities towards the oxidation of methanol, expressed both in terms of mass activity $\left(\mathrm{A} \cdot \mathrm{g}^{-1} \cdot \mathrm{Pt}\right)$ and specific activity $\left(\mathrm{mA} \cdot \mathrm{cm}^{-2} \cdot \mathrm{Pt}\right)$.

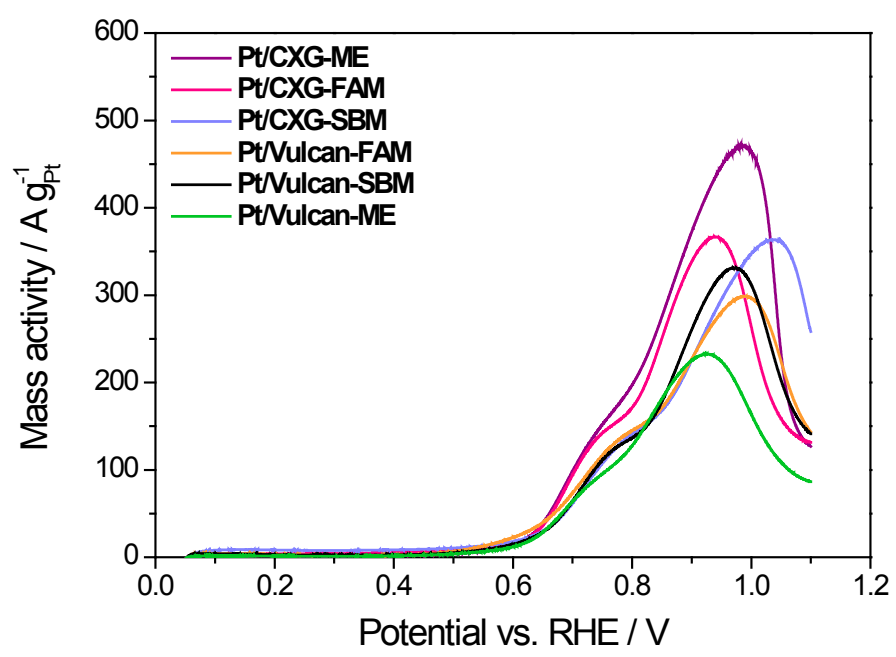

Figure 4. Cyclic voltammograms in a $2 \mathrm{M} \mathrm{CH}_{3} \mathrm{OH}+0.5 \mathrm{M} \mathrm{H}_{2} \mathrm{SO}_{4}$ solution for the assessed catalysts. Scan rate $=0.02 \mathrm{~V} \cdot \mathrm{s}^{-1}$.

The highest mass activity value is obtained with Pt/CXG-ME catalyst. This higher activity might be due to its higher activity towards the oxidation of $\mathrm{CO}$, an intermediate of $\mathrm{CH}_{3} \mathrm{OH}$ oxidation reaction. Since this catalyst presents the highest activity towards $\mathrm{CO}$ oxidation, $\mathrm{CH}_{3} \mathrm{OH}$ oxidation becomes also speeded up. Catalysts supported on carbon xerogels, whatever the synthetic method employed, are more active than catalysts supported on Vulcan. The higher mesopore volume of carbon xerogels, allowing an optimal diffusion of reagents towards the catalytic centres, is responsible for the higher catalytic activity. Among the different methods, both impregnation routes (FAM and SBM) lead to catalysts with similar behaviours, particularly when using CXG as catalyst support. Pt/CXG-FAM and Pt/Vulcan-SBM present very similar crystal sizes. Pt/Vulcan-SBM presents a better metal dispersion, (due to its lower crystal size) and so a slightly higher ECSA. In spite of this, its performance is lower, due to the higher mesopore volume of the carbon xerogel in comparison to the carbon black Vulcan. In the $\mathrm{CXG}$, Pt particles are better located within the three phase boundaries, where Pt is in contact with both the ionomer, nafion, and $\mathrm{CH}_{3} \mathrm{OH}$, favoring a higher catalytic activity. The catalyst $\mathrm{Pt} / \mathrm{Vulcan}-\mathrm{ME}$, showed the poorest activity, probably due to its bad metallic distribution, as could be seen in TEM 
micrographs. Regarding the specific activity, calculated dividing mass activity by the ECSA, catalysts with the lower ECSA show the higher specific activity, as a result of dividing by a lower value.

The activity of these catalysts towards methanol oxidation was also analyzed by chronoamperometric tests at $600 \mathrm{mV}$ as shown in Figure 5. As in the $\mathrm{CV}$ tests, Pt/CXG-ME showed the highest activity. Nevertheless, this activity did not seem very stable with time, given the certain activity decay observed during the experiment.

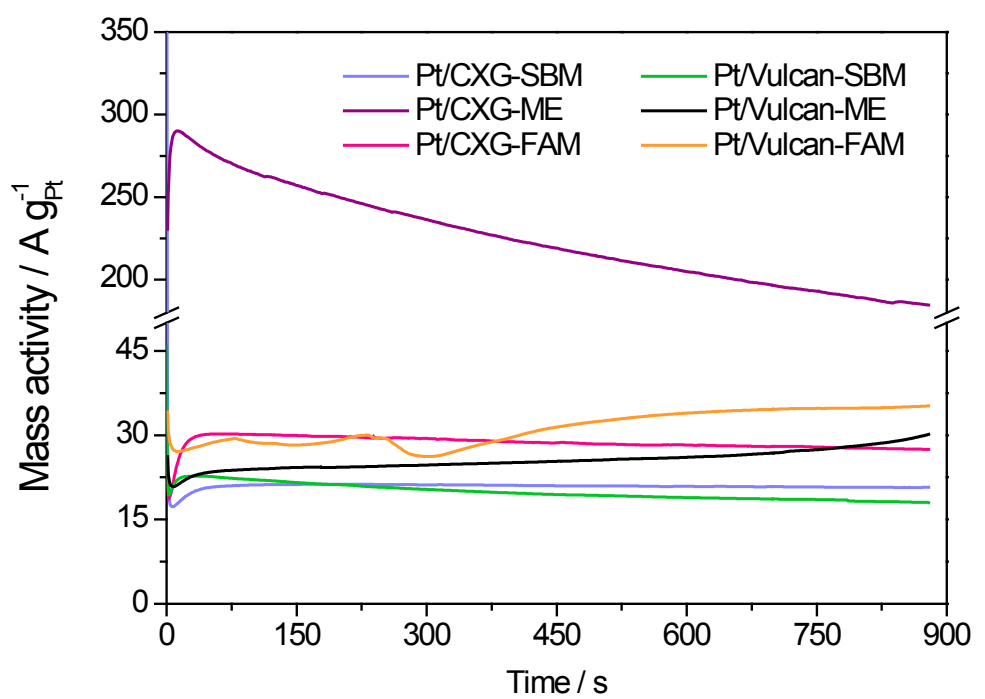

Figure 5. Chroamperometric tests performed at $0.6 \mathrm{~V} v s$. $\mathrm{RHE}$ in a $2 \mathrm{M} \mathrm{CH}_{3} \mathrm{OH}+0.5 \mathrm{M}$ $\mathrm{H}_{2} \mathrm{SO}_{4}$ solution for the assessed catalysts.

\section{Experimental Section}

\subsection{Synthesis of Carbon Xerogels}

Resorcinol (1,3-dihydroxybenzoic acid)-formaldehyde organic gels were synthesized by the sol-gel method first proposed by Pekala et al. [8]. The necessary amounts of resorcinol (R) (98\% Sigma-Aldrich, St. Louis, MO, USA) and sodium carbonate deca-hydrated (Panreac, Castellar del Vallès (Barcelona, Spain)) $(\mathrm{C})$ (molar ratio $\mathrm{R} / \mathrm{C}=800$ ) were dissolved in deionised water under stirring. Subsequently, the required volume of formaldehyde (F) $\left(37\right.$ wt. $\%$ in $\mathrm{H}_{2} \mathrm{O}$, contains $10 \%-15 \%$ Methanol as stabilizer, Sigma-Aldrich, St. Louis, MO, USA) (molar ratio resorcinol/formaldehyde R/F $=0.5$, and dilution rate equal 5.7, as described elsewhere [15]) was added to the former mixture and $\mathrm{pH}$ was adjusted to 6 with an aqueous solution of $2 \mathrm{M} \mathrm{HNO}_{3}$. The mixture was stirred for 30 min and then poured into sealed flasks, followed by curing for $24 \mathrm{~h}$ at room temperature, $24 \mathrm{~h}$ at $50{ }^{\circ} \mathrm{C}$ and 3 days at $85{ }^{\circ} \mathrm{C}$ until curing was complete as described elsewhere [16]. Afterwards gels were washed with acetone for three days to exchange the initial solvent, water. Acetone was daily replaced after vacuum filtration. This procedure allows keeping the original gel structure, as surface tension caused by evaporation of the solvent is lower for acetone than for water [6]. Finally wet gels were sub-critically dried at $110{ }^{\circ} \mathrm{C}$ for $5 \mathrm{~h}$. Organic xerogels are grinded prior to the treatment with acetone and after the drying process, in an agate mortar until a fine powder is obtained. Xerogels were pyrolyzed with the 
following heating program steps: (1) $2 \mathrm{~h}$ at $150{ }^{\circ} \mathrm{C}$; (2) $1 \mathrm{~h}$ at $300{ }^{\circ} \mathrm{C}$; (3) $1 \mathrm{~h}$ at $600{ }^{\circ} \mathrm{C}$; and (4) $2 \mathrm{~h}$ at $800{ }^{\circ} \mathrm{C}$ as described elsewhere [17].

\subsection{Pt catalysts Synthesis}

Pt was deposited on former carbon supports by impregnation and reduction with two different reducing agents: sodium borohydride and formic acid. The amount of metallic precursor was calculated to obtain a metal loading of $20 \% \mathrm{w} / \mathrm{w}$. An aqueous solution of $\mathrm{H}_{2} \mathrm{PtCl}_{6}$ (Sigma-Aldrich, St. Louis, MO, USA) was slowly added to a dispersion of the carbon support in ultrapure water. Mixture was sonicated during the addition of the metallic precursor. $\mathrm{pH}$ was adjusted to 5 with a solution of $\mathrm{NaOH}$. Subsequently, sodium borohydride was added in excess to reduce the metallic precursor, maintaining temperature under $18{ }^{\circ} \mathrm{C}$. Finally, catalyst was filtered and thoroughly washed with deionized water, and dried overnight at $60{ }^{\circ} \mathrm{C}$. The catalyst so obtained was named Pt/C-SBM, being $\mathrm{C}, \mathrm{CXG}$ or Vulcan.

When using formic acid as reducing agent, a dispersion of the carbon support in a $2 \mathrm{M}$ solution of formic acid was prepared and heated at $80^{\circ} \mathrm{C}$. Then an aqueous solution of $\mathrm{H}_{2} \mathrm{PtCl}_{6}$ (Sigma-Aldrich, St. Louis, MO, USA) was slowly added under magnetic stirring. Catalyst were filtered and thoroughly washed with ultrapure water, and dried overnight at $60{ }^{\circ} \mathrm{C}$. The catalyst so obtained was named $\mathrm{Pt} / \mathrm{C}-\mathrm{FAM}$.

The microemulsion route consisted on the synthesis of Pt nanoparticles by means of a water in oil microemulsion [18]. The microemulsion was composed of a commercial surfactant, n-heptane as the non-polar phase and 2-propanol as co-surfactant. A commercial surfactant (Brij30, Sigma-Aldrich, St. Louis, MO, USA) and n-heptane were mixed and stirred, before adding dropwise an aqueous solution of $\mathrm{H}_{2} \mathrm{PtCl}_{6}(8 \mathrm{mM})$. The co-surfactant, 2-propanol was added until an optically transparent mixture was observed, indicating the formation of the microemulsion. The whole mixture was stirred for $4 \mathrm{~h}$, after which an $0.1 \mathrm{M}$ aqueous solution of the reducing agent $\left(\mathrm{NaBH}_{4}\right)$ was slowly added to the microemulsion under continuous stirring. Finally this suspension was slowly added to a suspension of the carbon support in ethanol under sonication. The catalyst was thoroughly washed with ethanol and water and subsequently dried overnight at $60{ }^{\circ} \mathrm{C}[19]$. The catalyst so obtained was named Pt/C-ME.

\subsection{Carbon Supports and Catalysts Textural, Structural and Morphological Characterization}

The nature and characteristics of the carbon supports were characterized using nitrogen physisorption. Textural properties such as specific surface area, pore volume and mesoporosity were calculated from nitrogen adsorption-desorption isotherms, measured at $-196{ }^{\circ} \mathrm{C}$ using a Micromeritics (Norcross, GA, USA) ASAP 2020. Total surface area and pore volume were determined using the Brunauer-Emmet-Teller (BET) equation and the single point method, respectively. Microporosity was determined using the t-plot method and mesopore volume and medium pore size were calculated by applying the Barret-Joyner-Hallenda method. Catalysts were characterized by X-Ray Diffraction (XRD), and XRD patterns were performed using a Bruker (Billerica, MA, USA) AXS D8 Advance diffractometer, with a $\theta-\theta$ configuration and using $\mathrm{Cu} K \alpha$ radiation. Particle sizes were evaluated using TEM images obtained in a JEOL (Tokyo, Japan) 2100F microscope operated with an accelerating voltage of $200 \mathrm{kV}$ and equipped with a field emission electron gun providing a point resolution of $0.19 \mathrm{~nm}$. 
The standard procedure involved dispersing $3 \mathrm{mg}$ of the sample in ethanol in an ultrasonic bath for $15 \mathrm{~min}$. The sample was then placed in a $\mathrm{Cu}$ carbon grid where the liquid phase was evaporated.

\subsection{Electrochemical Characterization}

Catalyst electrochemical activity towards the oxidation of carbon monoxide and methanol was studied using cyclic voltammetry and chronoamperometry. A flow cell with a three-electrode assembly at room temperature and an AUTOLAB (Utrecht, The Netherlands) potentiostat-galvanostat were used to carry out the electrochemical characterization. The counter electrode consisted of a pyrolytic graphite bar and the reference electrode was a reversible hydrogen electrode (RHE). All potentials in the text refer to the latter. The working electrode consisted of a pyrolytic graphite disk with a thin layer of the different electrocatalysts deposited onto it. For the preparation of this layer, an aqueous suspension of Pt/CXG or Pt/Vulcan catalysts was obtained by ultrasonically dispersing it in Nafion and ultrapure water (Merck-Millipore, Billerica, MA, USA). Subsequently, an aliquot of $40 \mu \mathrm{L}$ of the dispersed suspension was deposited on top of the graphite disk $(7 \mathrm{~mm})$ and dried under inert atmosphere prior its use. After preparation, the electrode was immersed into deaerated $0.5 \mathrm{M} \mathrm{H}_{2} \mathrm{SO}_{4}$ electrolyte, prepared from high purity reagents (Merck-Millipore, Billerica, MA, USA) and ultrapure water (Merck-Millipore, Billerica, MA, USA). The electrolyte was saturated with pure $\mathrm{N}_{2}$ or CO $(99.997 \%$, Air Liquide, Madrid, Spain), depending on the experiments. Activation of the electrode was performed by potential cycling solution between 0.05 and $1.10 \mathrm{~V}$ at a scan rate of $0.5 \mathrm{~V} \cdot \mathrm{s}^{-1}$ until a stable voltammogram in the base electrolyte $\left(0.5 \mathrm{M} \mathrm{H}_{2} \mathrm{SO}_{4}\right)$ was obtained.

CO stripping voltammograms were obtained after bubbling this gas in the cell for 10 min at $0.20 \mathrm{~V}$, followed by electrolyte exchange and nitrogen purging to remove the excess of $\mathrm{CO}$, and oxidation by scanning the potential up to the upper limit previously established for Pt catalysts. The admission potential was selected considering that, for this value, maximum adsorbate coverage is achieved for $\mathrm{CO}$ adsorption on Pt. Electrochemical $\mathrm{Pt}$ active areas were determined from the integration of the current involved in the oxidation of a $\mathrm{CO}$ monolayer taking into account that $\mathrm{CO}$ adsorbs on $\mathrm{Pt}$ and assuming $420 \mu \mathrm{C} \cdot \mathrm{cm}^{-2}$. Cyclic voltammograms for the electrooxidation of methanol were carried out in a $2 \mathrm{M} \mathrm{CH} 3 \mathrm{OH}+0.5 \mathrm{M} \mathrm{H}_{2} \mathrm{SO}_{4}$ solution, at scan rate of $0.02 \mathrm{~V} \cdot \mathrm{s}^{-1}$, between 0.0 and $1.10 \mathrm{~V}$. Chronoamperometries were performed at $0.60 \mathrm{~V} v s$. RHE in a $2 \mathrm{M} \mathrm{CH}_{3} \mathrm{OH}+0.5 \mathrm{M} \mathrm{H}_{2} \mathrm{SO}_{4}$ solution in order to evaluate the performance of the electrocatalysts for the oxidation of methanol. Every experiment was carried out at room temperature $\left(25^{\circ} \mathrm{C} \pm 1{ }^{\circ} \mathrm{C}\right)$.

\section{Conclusions}

A highly mesoporous carbon xerogel was synthesized as support for Pt nanoparticles. Three different synthetic methodologies were employed for the synthesis of Pt-based catalysts: two impregnation methods and a microemulsion method. These methods were also applied to a commercial carbon black, Vulcan.

Carbon xerogel showed a high developed surface area and high mesoporosity, much greater than the one shown for the commercial support.

Catalysts supported on carbon xerogel provided lower crystal sizes and good metallic distribution, particularly when using formic acid as reducing agent. 
Pt-based catalysts were tested for $\mathrm{CO}$ oxidation and the $\mathrm{CH}_{3} \mathrm{OH}$ oxidation. Pt synthesized by the microemulsion method supported on the carbon xerogel was the highest active catalyst for the oxidation of $\mathrm{CH}_{3} \mathrm{OH}$. This fact was explained by the higher activity of this catalyst towards the oxidation of $\mathrm{CO}$, an intermediate of the oxidation of methanol.

Catalysts supported on carbon xerogels were more active than catalysts supported on the commercial carbon black support, Vulcan, due to the higher mesoporosity of the former, favoring the diffusion of reagents to and from the catalytic centers.

\section{Acknowledgments}

The authors wish to thank the Spanish Ministry of Economy and Competitiveness (Secretaría de Estado de I+D+I) and FEDER for financial support under the project CTQ2011-28913-C02-01.

\section{Author Contributions}

C.A. performed the synthesis and characterization of both carbon xerogels and catalysts assessed. The whole work was supervised by M.E.G, R.M. and M.J.L.

\section{Conflicts of Interest}

The authors declare no conflict of interest.

\section{References}

1. Job, N.; Ribeiro Pereira, M.F.; Lambert, S.; Cabiac, A.; Delahay, G.; Colomer, J.-F.; Marien, J.; Figueiredo, J.L.; Pirard, J.-P. Highly dispersed platinum catalysts prepared by impregnation of texture-tailored carbon xerogels. J. Catal. 2006, 240, 160-171.

2. Figueiredo, J.L.; Ribeiro Pereira, M.F.; Serp, P.; Kalck, P.; Samant, P.V.; Fernandes, J.B. Development of carbon nanotube and carbon xerogel supported catalysts for the electro-oxidation of methanol in fuel cells. Carbon 2006, 44, 2516-2522.

3. Samant, P.V.; Fernandes, J.B.; Rangel, C.M.; Figueiredo, J.L. Carbon xerogel supported Pt and $\mathrm{Pt}-\mathrm{Ni}$ catalysts for electro-oxidation of methanol in basic medium. Catal. Today 2005, 102-103, 173-176.

4. Sebastián, D.; Suelves, I.; Lázaro, M.J.; Moliner, R. Carbon nanofibers as electrocatalyst support for fuel cells: Effect of hydrogen on their properties in $\mathrm{CH}_{4}$ decomposition. J. Power Sources 2009, 192, 51-56.

5. Arbizzani, C.; Beninati, S.; Manferrari, E.; Soavi, F.; Mastragostino, M. Cryo- and xerogel carbon supported PtRu for DMFC anodes. J. Power Sources 2007, 172, 578-579.

6. Al-Muhtaseb, S.A.; Ritter, J.A. Preparation and Properties of Resorcinol-Formaldehyde Organic and Carbon Gels. Adv. Mater. 2003, 15, 101-114.

7. Antolini, E. Carbon supports for low-temperature fuel cell catalysts. Appl. Catal. B 2009, 88, 1-24.

8. Pekala, R.W. Organic aerogels from the polycondensation of resorcinol with formaldehyde. J. Mater. Sci. 1989, 24, 3221-3227. 
9. Alegre, C.; Calvillo, L.; Moliner, R.; González-Expósito, J.A.; Guillén-Villafuerte, O.; Martínez Huerta, M.V.; Pastor, E.; Lázaro, M.J. Pt and PtRu electrocatalysts supported on carbon xerogels for direct methanol fuel cells. J. Power Sources 2011, 196, 4226-4235.

10. Yoshizawa, N.; Hatori, H.; Soneda, Y.; Hanzawa, Y.; Kaneko, K.; Dresselhaus, M.S. Structure and electrochemical properties of carbon aerogels polymerized in the presence of $\mathrm{Cu}^{2+}$. J. Non-Cryst. Solids 2003, 330, 99-105.

11. Job, N.; Marie, J.; Lambert, S.; Berthon-Fabry, S.; Achard, P. Carbon xerogels as catalyst supports for PEM fuel cell cathode. Energy Convers. Manag. 2008, 49, 2461-2470.

12. Job, N.; Lambert, S.; Chatenet, M.; Gommes, C.; Maillard, F.; Berthon-Fabry, S.; Regalbuto, J.R.; Pirard, J.P. Preparation of highly loaded Pt/carbon xerogel catalysts for Proton Exchange Membrane fuel cells by the Strong Electrostatic Adsorption method. Catal. Today 2009, 150, 119-127.

13. Maillard, F.; Savinova, E.R.; Simonov, P.A.; Zaikovskii, V.I.; Stimming, U. Infrared Spectroscopic Study of CO Adsorption and Electro-oxidation on Carbon-Supported $\mathrm{Pt}$ Nanoparticles: Interparticle versus Intraparticle Heterogeneity. J. Phys. Chem. 2004, 108, 1789317904.

14. Maillard, F.; Schreier, S.; Savinova, E.R.; Weinkauf, S.; Stimming, U. Influence of particle agglomeration on the catalytic activity of carbon-supported $\mathrm{Pt}$ nanoparticles in $\mathrm{CO}$ monolayer oxidation. Phys. Chem. Chem. Phys. 2005, 7, 385-393.

15. Job, N.; Théry, A.; Pirard, R.; Marien, J.; Kocon, L.; Rouzaud, J.N.; Béguin, F.; Pirard, J.P. Carbon aerogels, cryogels and xerogels: Influence of the drying method on the textural properties of porous carbon materials. Carbon 2005, 43, 2481-2494.

16. Morales-Torres, S.; Maldonado-Hódar, F.J.; Pérez-Cadenas, A.F.; Carrasco-Marín, F. Structural characterization of carbon xerogels: From film to monolith. Microporous Mesoporous Mater. 2012, 153, 24-29.

17. Gorgulho, H.F.; Gonçalves, F.; Pereira, M.F.R.; Figueiredo, J.L. Synthesis and characterization of nitrogen-doped carbon xerogels. Carbon 2009, 47, 2032-2039.

18. Sebastián, D.; Alegre, C.; Calvillo, L.; Pérez, M.; Moliner, R.; Lázaro, M.J. Carbon supports for the catalytic dehydrogenation of liquid organic hydrides as hydrogen storage and delivery system. Int. J. Hydrog. Energy 2013, 39, 4109-4115.

19. Sebastián, D.; Lázaro, M.J.; Suelves, I.; Moliner, R.; Baglio, V.; Stassi, A.; Aricò, A.S. The influence of carbon nanofiber support properties on the oxygen reduction behavior in proton conducting electrolyte-based direct methanol fuel cells. Int. J. Hydrog. Energy 2012, 37, 6253-6260.

(C) 2015 by the authors; licensee MDPI, Basel, Switzerland. This article is an open access article distributed under the terms and conditions of the Creative Commons Attribution license (http://creativecommons.org/licenses/by/4.0/). 